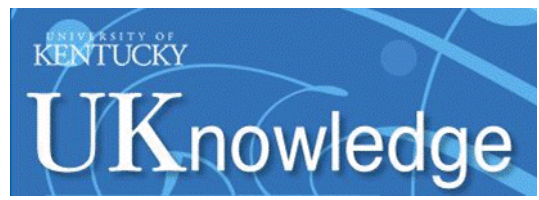

University of Kentucky

UKnowledge

Chemical and Materials Engineering Faculty

Publications

Chemical and Materials Engineering

2-21-2014

\title{
Toward Tuning the Surface Functionalization of Small Ceria Nanoparticles
}

\author{
Xing Huang \\ University of Kentucky, jerry.x.huang@uky.edu \\ Binghui Wang \\ University of Kentucky, binghui.wang@uky.edu \\ Eric A. Grulke \\ University of Kentucky, eric.grulke@uky.edu \\ Matthew J. Beck \\ University of Kentucky, mjbe223@uky.edu
}

Follow this and additional works at: https://uknowledge.uky.edu/cme_facpub

Right click to open a feedback form in a new tab to let us know how this document benefits you.

\section{Repository Citation}

Huang, Xing; Wang, Binghui; Grulke, Eric A.; and Beck, Matthew J., "Toward Tuning the Surface Functionalization of Small Ceria Nanoparticles" (2014). Chemical and Materials Engineering Faculty Publications. 2.

https://uknowledge.uky.edu/cme_facpub/2

This Article is brought to you for free and open access by the Chemical and Materials Engineering at UKnowledge. It has been accepted for inclusion in Chemical and Materials Engineering Faculty Publications by an authorized administrator of UKnowledge. For more information, please contact UKnowledge@lsv.uky.edu. 


\section{Toward Tuning the Surface Functionalization of Small Ceria Nanoparticles}

\section{Digital Object Identifier (DOI)}

http://dx.doi.org/10.1063/1.4864378

\section{Notes/Citation Information}

Published in Journal of Chemical Physics, v. 140, no. 7, 074703.

Copyright 2014 American Institute of Physics. This article may be downloaded for personal use only. Any other use requires prior permission of the author and the American Institute of Physics.

This article appeared in J. Chem. Phys. 140, 074703 (2014) and may be found at http://dx.doi.org/ $10.1063 / 1.4864378$. 


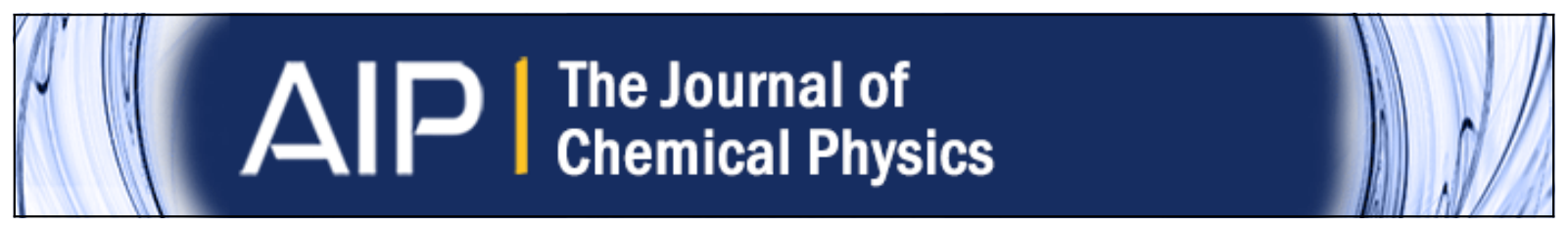

\section{Toward tuning the surface functionalization of small ceria nanoparticles}

Xing Huang, Binghui Wang, Eric A. Grulke, and Matthew J. Beck

Citation: The Journal of Chemical Physics 140, 074703 (2014); doi: 10.1063/1.4864378

View online: http://dx.doi.org/10.1063/1.4864378

View Table of Contents: http://scitation.aip.org/content/aip/journal/jcp/140/7?ver=pdfcov

Published by the AIP Publishing

Articles you may be interested in

Influence of solvent on the morphology and photocatalytic properties of $\mathrm{ZnS}$ decorated $\mathrm{CeO} 2$ nanoparticles J. Appl. Phys. 115, 213514 (2014); 10.1063/1.4880795

Modifying ceria (111) with a TiO2 nanocluster for enhanced reactivity

J. Chem. Phys. 139, 184710 (2013); 10.1063/1.4829758

Direct observation of blocked nanoscale surface evaporation on SiO2 nanodroplets

Appl. Phys. Lett. 101, 183114 (2012); 10.1063/1.4765662

Diamond nanoparticles with more surface functional groups obtained using carbon nanotubes as sources J. Appl. Phys. 110, 054321 (2011); 10.1063/1.3636103

Introduction to the Surface Spectra of Lanthanide-Based Materials

Surf. Sci. Spectra 16, i (2009); 10.1116/11.20110901

\section{AlP Re-register for Table of Content Alerts}




\title{
Toward tuning the surface functionalization of small ceria nanoparticles
}

\author{
Xing Huang, ${ }^{1}$ Binghui Wang, ${ }^{1}$ Eric A. Grulke, ${ }^{1,2}$ and Matthew J. Beck ${ }^{1,2, a)}$ \\ ${ }_{1}^{1}$ Department of Chemical and Materials Engineering, University of Kentucky, Lexington, Kentucky 40506, USA \\ ${ }^{2}$ Center for Computational Sciences, University of Kentucky, Lexington, Kentucky 40506, USA
}

(Received 1 April 2013; accepted 8 January 2014; published online 18 February 2014)

\begin{abstract}
Understanding and controlling the performance of ceria nanoparticle (CNP) catalysts requires knowledge of the detailed structure and property of CNP surfaces and any attached functional groups. Here we report thermogravimetric analysis results showing that hydrothermally synthesized $\sim 30 \mathrm{~nm}$ CNPs are decorated with 12.9 hydroxyl groups per $\mathrm{nm}^{2}$ of CNP surface. Quantum mechanical calculations of the density and distribution of bound surface groups imply a scaling relationship for surface group density that balances formal charges in the functionalized CNP system. Computational results for CNPs with only hydroxyl surface groups yield a predicted density of bound hydroxyl groups for $\sim 30 \mathrm{~nm}$ CNPs that is $\sim 33 \%$ higher than measured densities. Quantitative agreement between predicted and measured hydroxyl surface densities is achieved when calculations consider CNPs with both $-\mathrm{OH}$ and $-\mathrm{O}_{x}$ surface groups. For this more general treatment of CNP surface functionalizations, quantum mechanical calculations predict a range of stable surface group configurations that depend on the chemical potentials of $\mathrm{O}$ and $\mathrm{H}$, and demonstrate the potential to tune CNP surface functionalizations by varying temperature and/or partial pressures of $\mathrm{O}_{2}$ and $\mathrm{H}_{2} \mathrm{O}$. ( 2014 AIP Publishing LLC. [http://dx.doi.org/10.1063/1.4864378]
\end{abstract}

\section{INTRODUCTION}

The design and development of low-cost but highly active and selective catalysts continues to be a major focus of efforts in materials chemistry. Cerium dioxide $\left(\mathrm{CeO}_{2}\right.$, ceria), and ceria-based materials are widely exploited as exactly such catalysts in $\mathrm{CO}$ oxidation, ${ }^{1}$ photocatalytic water splitting, ${ }^{2}$ the water-gas-shift reaction, ${ }^{3}$ solid oxide fuel cells, ${ }^{4}$ and, increasingly, oxygen-radical scavenging in biomedical applications. ${ }^{5,6}$ As with all catalysts, the efficacy of ceria in catalyzing desirable reactions is driven by surface chemistry, and therefore depends strongly on the structure of ceria surfaces themselves. In general, the detailed atomic structure of ceria surfaces under reaction conditions is not well known, and the precise role of surface functional groups in controlling catalytic reactions is unclear.

As highly active ceria nanoparticles (CNPs) are generally synthesized and applied in aqueous or humid environments, the potential role of surface adsorbed hydroxyl groups is highly relevant, particularly with reference to ceria-catalyzed reactions involving water-related species. ${ }^{7}$ Experiments using Fourier transform infrared spectroscopy (FTIR) and thermogravimetric analysis with mass spectroscopy (TGA-MS) have previously verified the presence of surface adsorbed hydroxyl groups on CNPs, and estimated their binding energies and surface densities. ${ }^{8-10}$ These techniques, though, are not able to directly reveal the structure of hydroxyl-covered ceria surfaces, ${ }^{11,12}$ nor the chemistry controlling the adsorption, distribution, and stable surface densities of hydroxyl groups as a function of environmental conditions. Quantum mechanical calculations of atomic structures and formation energies have been widely applied to study the structures and ener-

\footnotetext{
a)Electronic mail: m.beck@uky.edu.
}

getics of ceria surfaces, ${ }^{13,14}$ and can be combined with experimental synthesis and characterization methods, as well as thermochemical data, to address these limitations.

Here we report experimental measurements of the surface density of hydroxyl groups bound to $\sim 30 \mathrm{~nm}$ CNPs as well as quantum mechanical calculations of the density and distribution of both $-\mathrm{OH}$ and $-\mathrm{O}_{x}$ surface groups at surfaces of similar small CNPs. Calculated structures and charge densities imply that the equilibrium density of bound surface groups is dictated by a balance between (i) formal positive charges on $\mathrm{Ce}$ atoms and (ii) formal negative charges on "bulk" $\mathrm{O}$ atoms as well as any adsorbed surface groups. This allows the formulation of a set of scaling relationships for predicting the density of bound hydroxyl surface groups as a function of CNP size and functional group configuration. For systems where only hydroxyl surface groups are present, predicted surface group densities for the $\sim 30 \mathrm{~nm}$ CNPs synthesized here are $\sim 33 \%$ higher than experimentally measured densities. Allowing for the presence of surface groups other than hydroxyl groups rectifies this discrepancy.

Combining calculated formation energies with previously tabulated thermochemical data, we therefore construct a phase diagram for CNP surface configurations containing both $-\mathrm{OH}$ and $-\mathrm{O}_{x}$ surface groups as a function of $\mathrm{O}$ and $\mathrm{H}$ chemical potentials. In neutral oxygen- and water-containing environments, $\mathrm{O}$ and $\mathrm{H}$ chemical potentials are determined by the temperature (T), $\mathrm{O}_{2}$ partial pressure $\left(p_{\mathrm{O}_{2}}\right)$, and $\mathrm{H}_{2} \mathrm{O}$ partial pressure $\left(p_{\mathrm{H}_{20}}\right)$ in effect during CNP synthesis or application. Based on the values of these parameters during their synthesis, the $\sim 30 \mathrm{~nm}$ CNPs studied here are predicted to have mixed $-\mathrm{OH}$ and $-\mathrm{O}_{x}$ surface configurations, and accounting for this brings the computationally-predicted and experimentally measured surface hydroxyl group densities into quantitative agreement. These results highlight the importance of 
environmental conditions in controlling the density and distribution of surface groups bound to small CNPs. In turn, this suggests that intrinsic CNP surface functionalizations can be tuned by manipulating environmental conditions (namely $\mathrm{T}$, $p_{\mathrm{O}_{2}}$ and $p_{\mathrm{H}_{2} \mathrm{O}}$, as considered here, as well as $\mathrm{pH}$, etc.) within experimentally accessible ranges.

\section{EXPERIMENTAL AND THEORETICAL METHODS}

\section{A. Synthesis and characterization of CNPs}

We have synthesized small CNPs via the hydrothermal method developed by Mai et al. ${ }^{15}$ Cerium nitrate hexahydrate $\left(\mathrm{Ce}(\mathrm{NO})_{3} \cdot 6 \mathrm{H}_{2} \mathrm{O}\right.$, Puriss, Fluka Analytical) was used as the cerium source. $1.737 \mathrm{~g} \mathrm{Ce}(\mathrm{NO})_{3} \cdot 6 \mathrm{H}_{2} \mathrm{O}(0.004 \mathrm{~mol})$ was dissolved into $10 \mathrm{ml}$ ultra deionized water and stirred for $10 \mathrm{~min}$. $16.8 \mathrm{~g} \mathrm{NaOH}$ was dissolved into $70 \mathrm{ml}$ ultra deionized water and stirred for $10 \mathrm{~min}$ to form $6 \mathrm{~mol} \mathrm{~L}^{-1}$ solution. The $\mathrm{NaOH}$ solution was cooled to room temperature before other use. Then, $\mathrm{Ce}(\mathrm{NO})_{3}$ was added dropwise into $\mathrm{NaOH}$ solution under constant stirring. The mixture was stirred for $30 \mathrm{~min}$ with the formation of a milky slurry. It was then transferred to a teflon bottle and packed into a stainless steel autoclave. The autoclave was heated to $180{ }^{\circ} \mathrm{C}$ for $24 \mathrm{~h}$. The resulting white precipitate was separated by centrifugation, washed with water three times and ethanol twice, followed by drying at $75^{\circ} \mathrm{C}$ in air overnight. The final product is yellowish powder, which is stable during storage.

For determining the primary particle size of synthesized CNPs, both transmission electron microscopy (JEOL-2010), and scanning electron microscopy (Hitachi-4300) were employed. The dried powders were also characterized by thermogravimetric analysis (TGA 7, Perkin Elmer) to obtain the change of their weight as a function of temperature. The ceria sample was heated in a nitrogen environment from $30{ }^{\circ} \mathrm{C}$ to $110{ }^{\circ} \mathrm{C}$ at $10{ }^{\circ} \mathrm{C} \mathrm{min}{ }^{-1}$, held at $110{ }^{\circ} \mathrm{C}$ for $30 \mathrm{~min}$ to remove physisorbed solvent and water, then heated to $720^{\circ} \mathrm{C}$ at $10{ }^{\circ} \mathrm{C}$ min $^{-1}$. The empty pan was also heated under the same conditions as background.

The X-ray diffraction (XRD) was used to characterize the crystal structure of synthesized CNPs. The dry ceria powder was dispersed in ethanol. Some drops of dispersion were placed on glass slide. After the ethanol evaporated, the thin ceria film was characterized by X-ray diffraction on Siemens D500 X-ray diffractometer, using $\mathrm{Cu} \mathrm{K}_{\alpha}$ radiation with $2 \theta$ from $10^{\circ}$ to $80^{\circ}$ at scan rate of $2^{\circ} \mathrm{min}^{-1}$ and step size of $0.05^{\circ}$.

FTIR, Thermo Nicolet Nexus 470 ESP was used to detect the functional groups at the surface of the as-synthesized $\sim 30 \mathrm{~nm}$ CNPs. Potassium bromide (KBr, Fisher Scientific) was used as pellet material. All samples and $\mathrm{KBr}$ were heated in a vacuum oven at $120{ }^{\circ} \mathrm{C}$ for $1 \mathrm{~h}$ to remove any adsorbed water. $3 \mathrm{mg}$ of as-synthesized ceria were mixed with $600 \mathrm{mg}$ $\mathrm{KBr} .60 \mathrm{mg}$ of the mixture was pressed to produce the pellets. After the pellets were produced, they were heated at $120{ }^{\circ} \mathrm{C}$ for $5 \mathrm{~min}$ to remove the water adsorbed during the preparation of pellets. The pellets were scanned by infrared spectroscopy from $400 \mathrm{~cm}^{-1}$ to $4000 \mathrm{~cm}^{-1}$ in dry air environment. The result shown in Figure 4(b) are in the adsorption format.
Thermogravimetric analysis (TGA 7, Perkin-Elmer) was used to obtain the change of as-synthesized CNPs weight as a function of temperature. During synthesis of CNPs, some $\mathrm{Ce}(\mathrm{OH})_{4}$ is always formed. It will dehydrate, so it can influence the TGA result. The dried ceria powder was heated at $500{ }^{\circ} \mathrm{C}$ for $2 \mathrm{~h}$ to remove the $\mathrm{Ce}(\mathrm{OH})_{4}$ since it decomposes from $150{ }^{\circ} \mathrm{C}$ to $450{ }^{\circ} \mathrm{C}$. ${ }^{16}$ Then the sample was kept in saturated water vapor for $48 \mathrm{~h}$ to repopulate the surface with hydroxyl groups. The final sample was named "neat ceria" and was characterized in a nitrogen environment using the same TGA procedure as for dry powders.

\section{B. Computational methods and models}

The structure and properties of small CNPs were calculated using the planewave density function theory code VASP. ${ }^{17}$ Exchange and correlation were described at the level of the generalized gradient approximation (GGA), using the Perdew-Burke-Ernzerhof (PBE) formalism. ${ }^{18}$ The Ce $4 f 5 s 5 p 5 d 6 s$, and $\mathrm{O} 2 p 2 s$ electrons were treated as valence electrons, and core-electron interactions were modeled using the projector-augmented wave method. ${ }^{19}$ The Hubbard $U$ correction as formulated by Duderev ${ }^{20}$ was applied to the $\mathrm{Ce}$ $4 f$ electrons with $U=5 \mathrm{eV} .^{21}$ The electronic wavefunctions were expanded in plane waves with a kinetic-energy cutoff of $400 \mathrm{eV}$. Reciprocal-space summations were performed at the $\Gamma$-point. All considered structures were relaxed without symmetry restrictions according to the calculated interatomic forces until maximum residual atomic forces were less than $0.04 \mathrm{eV}^{-1}$ and total energies were converged to within $10^{-4}$ $\mathrm{eV}$ atom $^{-1}$.

To enable stability comparisons among structures with different surface terminations, and to connect computed energies to physically relevant thermochemical data, the formation (binding) energy of bulk (cubic fluorite) $\mathrm{CeO}_{2}, E_{f}^{b u l k}$, is defined as

$$
E_{f}^{b u l k}\left(n_{\mathrm{Ce}}\right) \equiv E_{V A S P}^{b u l k}\left(n_{\mathrm{Ce}}\right)-n_{\mathrm{Ce}} \mu_{\mathrm{Ce}}-2 n_{\mathrm{Ce}} \mu_{\mathrm{O}} .
$$

Here, $E_{V A S P}^{\text {bulk }}\left(n_{\mathrm{Ce}}\right)$ is the calculated ground state energy of bulk cubic fluorite $\mathrm{CeO}_{2}$ with $n_{\mathrm{Ce}} \mathrm{Ce}$ atoms at $T=0 \mathrm{~K} . \mu_{\mathrm{Ce}}$ and $\mu_{\mathrm{O}}$ are the chemical potentials of $\mathrm{Ce}$ and $\mathrm{O}$ atoms, respectively. The formation energy of a CNP with an arbitrary Oand H-containing surface configuration, $E_{f}^{C N P}$, is similarly defined as

$$
E_{f}^{C N P}\left(n_{\mathrm{Ce}}\right) \equiv E_{V A S P}^{C N P}\left(n_{\mathrm{Ce}}\right)-n_{\mathrm{Ce}} \mu_{\mathrm{Ce}}-n_{\mathrm{O}} \mu_{\mathrm{O}}-n_{\mathrm{H}} \mu_{\mathrm{H}} .
$$

Here, $E_{V A S P}^{C N P}\left(n_{\mathrm{Ce}}\right)$ is the calculated ground state energy of CNPs with $n_{\mathrm{Ce}} \mathrm{Ce}$ atoms at $T=0 \mathrm{~K}$. Note that $n_{\mathrm{O}}$ includes both "bulk" $\mathrm{O}$ atoms within the CNP and any additional $\mathrm{O}$ atoms present at the surface. In addition, $\mu_{\mathrm{O}}$ and $\mu_{\mathrm{H}}$ are the chemical potentials of $\mathrm{O}$ and $\mathrm{H}$ atoms, respectively. They are fixed by the environment surrounding the CNP.

For clarity, in this study we reference the formation energy of various CNPs to that of bulk $\mathrm{CeO}_{2}$ with an equivalent number of $\mathrm{Ce}$ atoms. This gives an excess formation energy, $E_{e x}^{C N P}$, which, if negative, would imply that the CNP structure considered is more stable than bulk $\mathrm{CeO}_{2}$ in $a$ given environment-where $\mu_{\mathrm{O}}$ and $\mu_{\mathrm{H}}$ are determined by the 
environment specified. More generally, the lower the excess formation energy of a particular CNP configuration for particular values of $\mu_{\mathrm{O}}$ and $\mu_{\mathrm{H}}$, the more stable that configuration is compared to other CNP configurations,

$$
\begin{aligned}
E_{e x}^{C N P} \equiv & E_{f}^{C N P}\left(n_{\mathrm{Ce}}\right)-E_{f}^{b u l k}\left(n_{\mathrm{Ce}}\right) \\
= & E_{V A S P}^{C N P}\left(n_{\mathrm{Ce}}\right)-E_{V A S P}^{b u l k}\left(n_{\mathrm{Ce}}\right) \\
& -\left(n_{\mathrm{O}}-2 n_{\mathrm{Ce}}\right) \mu_{\mathrm{O}}-n_{\mathrm{H}} \mu_{\mathrm{H}} .
\end{aligned}
$$

In an environment containing $\mathrm{O}_{2}$ gas and $\mathrm{H}_{2} \mathrm{O}$ vapor, we can directly connect $\mu_{\mathrm{O}}$ and $\mu_{\mathrm{H}}$ to experimental thermochemical data (e.g., following Ref. 22). The $\mathrm{O}$ chemical potential is defined as

$$
\begin{aligned}
\mu_{\mathrm{O}}(T, p)= & 0.5 \mu_{\mathrm{O}_{2}}\left(T, p^{o}\right)+0.5 E_{V A S P}^{\mathrm{O}_{2}} \\
& +0.5 k T \ln \left(p_{\mathrm{O}_{2}} / p^{o}\right),
\end{aligned}
$$

in which $E_{V A S P}^{\mathrm{O}_{2}}$ is the ground state energy of $\mathrm{O}_{2}$ gas at $T=0 \mathrm{~K}$ with the same calculation parameters used for the CNP itself. $\mu_{\mathrm{O}_{2}}\left(T, p^{o}\right)$ is the experimentally measured chemical potential (including vibrational and rotational contributions) at $T$ and standard pressure. $p_{\mathrm{O}_{2}}$ is the actual partial pressure of $\mathrm{O}_{2}$ gas present in the system of interest. Equation (4), therefore, combines the density functional theory (DFT)calculated ground state energy with experimental thermochemical data to give the temperature- and partial-pressuredependent chemical potential of $\mathrm{O}$ appearing in Eq. (3). Similarly, the chemical potential of $\mathrm{H}_{2} \mathrm{O}$ vapor is defined as

$$
\mu_{\mathrm{H}_{2} \mathrm{O}}(T, p)=\mu_{\mathrm{H}_{2} \mathrm{O}}\left(T, p^{o}\right)+E_{V A S P}^{\mathrm{H}_{2} \mathrm{O}}+k T \ln \left(p_{\mathrm{H}_{2} \mathrm{O}} / p^{o}\right)
$$

again, where $E_{V A S P}^{\mathrm{H}_{2} \mathrm{O}}$ is the calculated ground state energy of $\mathrm{H}_{2} \mathrm{O}$ vapor at $T=0 \mathrm{~K}, \mu_{\mathrm{H}_{2} \mathrm{O}}\left(T, p^{o}\right)$ is the experimentally measured chemical potential at $T$ and standard pressure, and $p_{\mathrm{H}_{2} \mathrm{O}}$ is the partial pressure of $\mathrm{H}_{2} \mathrm{O}$ vapor in the system of interest.

At thermodynamic equilibrium and neutral $\mathrm{pH}, \mu_{\mathrm{H}}$, and $\mu_{\mathrm{O}}$ must be related by

$$
2 \mu_{\mathrm{H}}(T, p)+\mu_{\mathrm{O}}(T, p)=\mu_{\mathrm{H}_{2} \mathrm{O}}(T, p) .
$$

Thus, in a gas phase environment containing $\mathrm{O}_{2}$ gas and $\mathrm{H}_{2} \mathrm{O}$ vapor, we have

$$
2 \mu_{\mathrm{H}}+\mu_{\mathrm{O}}=\mu_{\mathrm{H}_{2} \mathrm{O}}\left(T, p^{o}\right)+E_{V A S P}^{\mathrm{H}_{2} \mathrm{O}}+k T \ln \left(p_{\mathrm{H}_{2} \mathrm{O}} / p^{o}\right) .
$$

Combining Eqs. (4) and (7), we write the chemical potential of $\mathrm{H}$ as

$$
\begin{aligned}
\mu_{\mathrm{H}}= & 0.5 \mu_{\mathrm{H}_{2} \mathrm{O}}\left(T, p^{o}\right)+0.5 E_{V A S P}^{\mathrm{H}_{2} \mathrm{O}}+0.5 k T \ln \left(p_{\mathrm{H}_{2} \mathrm{O}} / p^{o}\right) \\
& -0.25 \mu_{\mathrm{O}_{2}}\left(T, p^{o}\right)-0.25 E_{V A S P}^{\mathrm{O}_{2}}-0.25 k T \ln \left(p_{\mathrm{O}_{2}} / p^{o}\right)
\end{aligned}
$$

Combining Eq. (8) with Eq. (4) gives expressions for $\mu_{\mathrm{H}}$ and $\mu_{\mathrm{O}}$. Experimental values for $\mu_{\mathrm{O}_{2}}\left(T, p^{o}\right)$ and $\mu_{\mathrm{H}_{2} \mathrm{O}}\left(T, p^{o}\right)$ appearing above have been obtained from the NIST-JANAF Thermochemical Tables. ${ }^{23}$ Chemical potential values for temperatures not directly tabulated were linearly interpolated from values at the nearest tabulated temperatures.

In sum, the above equations give values for $\mu_{\mathrm{H}}$ and $\mu_{\mathrm{O}}$ that can be used in Eq. (3) to determine experimentally rel- evant excess formation energies for various CNP structures directly from knowledge of the $T, p_{\mathrm{O}_{2}}$ and $p_{\mathrm{H}_{2} \mathrm{O}}$ of an experimental system of interest. In this way, we combine DFT+U calculated structures and energies with thermochemical data to determine the relative stability of CNPs in environments containing $\mathrm{O}_{2}$ gas and $\mathrm{H}_{2} \mathrm{O}$ vapor.

\section{Construction of initial CNP structures for DFT calculation of ground state configurations}

The supercell approximation is used here to model isolated CNPs. In this approximation, a finite computational box (the supercell) is extended to infinity under periodic boundary conditions. The supercell contains a single nanoparticle surrounded by a vacuum layer. All nanoparticle structures considered here are built from cubic fluorite $\mathrm{CeO}_{2}$ bulk unit cells. The $\mathrm{CeO}_{2}$ unit cell exhibits $\mathrm{Fm} \overline{3} \mathrm{~m}$ symmetry, and contains $8 \times \frac{1}{8} \mathrm{Ce}$ atoms at the cell corners, $6 \times \frac{1}{2} \mathrm{Ce}$ atoms at the cell faces, and $8 \mathrm{O}$ atoms within the unit cell (Figure 1(a)). This unit cell is repeated in the three principal directions to construct a CNP of arbitrary size (Figure 1(b)). Cubic \{001\}terminated CNPs are considered, consistent with transmission electron microscopy (TEM) images of the experimental samples (see below). Calculation supercells contain a $\sim 1 \mathrm{~nm}, 32$ $\mathrm{Ce}$ atom, CNP exhibiting $6\{001\}$ facets. To ensure no interaction between CNPs in neighboring supercells, a vacuum layer of $\sim 1.5 \mathrm{~nm}$ surrounds each CNP (Figure 1(c)). A CNP "core" consisting of $32 \mathrm{Ce}$ atoms and 27 "internal bulk" O atoms is present in each considered CNP, and a range of different combinations of $-\mathrm{O}_{x}$ and/or $-\mathrm{OH}$ surface groups are placed at surface $\mathrm{O}$ lattice sites (Figure 1(d)).
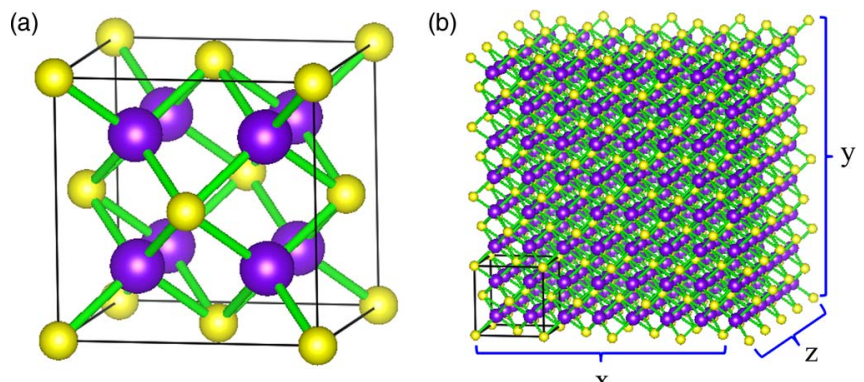

(c)

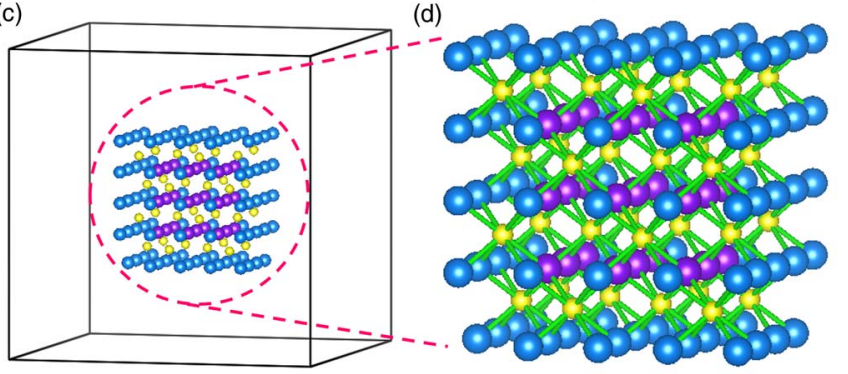

FIG. 1. (a) unit cell of bulk $\mathrm{CeO}_{2}$ showing cubic fluorite structure; (b) schematic illustration of building the solid atomic assembly of $\mathrm{Ce}$ and $\mathrm{O}$ atoms by randomly expanding the unit cell of bulk $\mathrm{CeO}_{2}$ (enclosed by black solid lines) $\mathrm{x}, \mathrm{y}$, and $\mathrm{z}$ times in three orthonormal directions, respectively; (c) the supercell of cubic CNPs of $\sim 1 \mathrm{~nm}$ for relaxation calculation; (d) zoomin image of the solid atomic assembly in (c) to show the atomic structure of $\{001\}$-terminated CNPs. Yellow balls represent Ce atoms, purple balls represent bulk $\mathrm{O}$ atoms, and blue balls represent all possible surface $\mathrm{O}$ lattice sites that can be partially or fully occupied by either individual $\mathrm{O}$ atoms or $-\mathrm{OH}$. 
It is important to note that the use of fully quantum mechanical DFT calculations means that $\mathrm{Ce}^{3+}$ and $\mathrm{Ce}^{4+}$ cations need not be identified a priori. All calculation supercells are constructed to be net neutral (that is, they exhibit no net charge). For a given atomic arrangement the present calculations solve for a minimum-energy distribution of valence electrons. Once this distribution has been computed, local charges can be assigned to specific atoms ${ }^{24}$ allowing the actual charge state of each atom to be determined as an output of DFT calculations. In addition, knowledge of the distribution of electrons allows the net Coulomb forces acting on each nucleus to be calculated. By moving the nuclei according to these interatomic forces, the ground state atomic arrangement can also be determined. Therefore, initial atomic arrangements are allowed to relax to their ground state structures, and all reported CNP energies are for (local) minimum energy atomic configurations. These structural relaxations are not constrained to any symmetry, and all relaxations retain the core cubic fluorite bulk structure within the CNPs.

Finally, it should be noted that the stable (low energy) oxidation state(s) of CNPs is (are) not assumed or constrained in the present calculations. The oxidation state of a CNP in a particular environment is directly determined by the energy cost of anions from the environment balanced against the energy variations of the CNP itself versus oxidation state. That is to say, when the cost of anions in, e.g., a reducing environment, exceeds the energy penalty for the creation of a $\mathrm{Ce}^{3+}$ cation, the stable CNP (with lowest excess formation energy) will be reduced (non-stoichiometric). The energy difference between Ce oxidation states is included in (and, in fact, not separable from) $E_{V A S P}^{C N P}$, above. Numerous reports demonstrate that the DFT+U method employed here accurately assesses this energy difference. ${ }^{25-27}$ In combination with the definition of $E_{e x}^{C N P}$ (Eq. (3) above), which includes experimentallyrelevant $\mathrm{O}$ and $\mathrm{H}$ chemical potentials $\left(\mu_{\mathrm{O}}\right.$ and $\left.\mu_{\mathrm{H}}\right)$, it is therefore not only possible to determine the stable arrangement of atoms in CNPs at fixed oxidation states, but also to determine the stable oxidation state of CNPs in a given environment (that is, for given values of $\mu_{\mathrm{O}}$ and $\mu_{\mathrm{H}}$ ).

In the present calculations, we cannot consider fully arbitrary environments, but are limited to gas phase environments containing only $\mathrm{O}_{2}$ and $\mathrm{H}_{2} \mathrm{O}$. We have also focused on one particular CNP shape, the $\{001\}$-terminated CNP cube, as this is the primary shape shown to be present in TEM images of the experimental samples considered. All CNPs considered here retain cubic fluorite structures after relaxation, again, consistent with experimental analyses of the reference samples. Therefore, within the above limitations, we reproduce experimental conditions to the extent possible while not assuming particular surface configurations or particular oxidation states. These CNP properties are rather solved for as a function of external conditions.

\section{RESULTS AND DISCUSSION}

\section{A. The morphology of synthesized $\sim 30 \mathrm{~nm}$ CNPs}

Figure 2 shows the shape and morphology of assynthesized CNPs. Scanning electron microscopy (SEM)

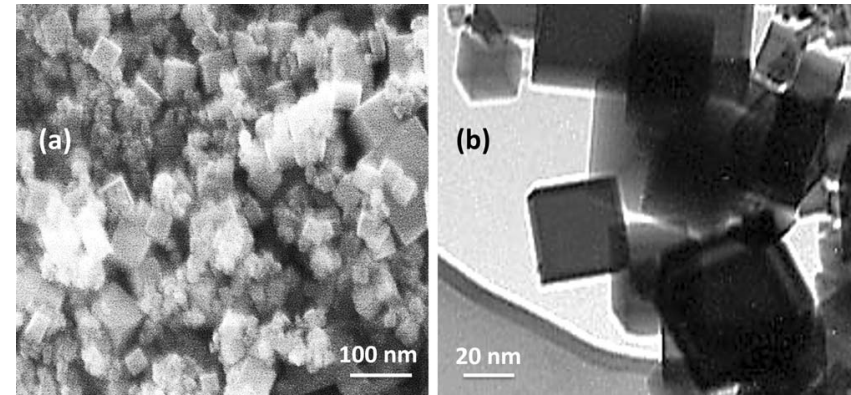

FIG. 2. SEM (a) and TEM (b) images of synthesized CNPs showing typical nanoparticle sizes of $20-40 \mathrm{~nm}$.

shows that as-synthesized CNPs are primarily cubic, with typical sizes ranging from 20 to $40 \mathrm{~nm}$, but also including some CNPs as small as $10 \mathrm{~nm}$ and as large as 100 $\mathrm{nm}$. A closer examination via TEM further confirms that assynthesized CNPs are primarily cubic. The crystal structure of as-synthesized CNPs is revealed through XRD analysis. The XRD pattern shown in Figure 3 reveals that the angle and intensity pattern of diffraction peaks are in agreement with those of the face-centered cubic (fluorite) structure of $\mathrm{CeO}_{2}$ powder (Cerianite, JCPDS 34-0394) with indexed peaks corresponding to (111), (200), (220), and (311) planes. In addition, the observed sharp and strong diffraction peaks suggest that CNP samples were highly crystalline. It is worth noting that the XRD data do not show the $(002) \mathrm{Ce}(\mathrm{OH})_{3}$ peak at $2 \theta=48^{\circ} .^{28}$ This effectively rules out the possibility of $\mathrm{Ce}(\mathrm{OH})_{3}$ (an independent compound, different from $\mathrm{Ce}^{3+}$ cation within $\mathrm{CeO}_{2}$ ) present in our samples.

\section{B. Experimental measurement of hydroxyl surface group density on CNPs}

Thermogravimetric analysis (TGA) was conducted on as-synthesized CNPs to experimentally estimate the number of hydroxyl groups adsorbed on the CNP surfaces. Figure 4(a) shows representative weight loss from "neat" CNPs as a function of temperature. A total of $0.18 \%$ weight loss was observed for temperatures up to $110{ }^{\circ} \mathrm{C}$, and this loss was

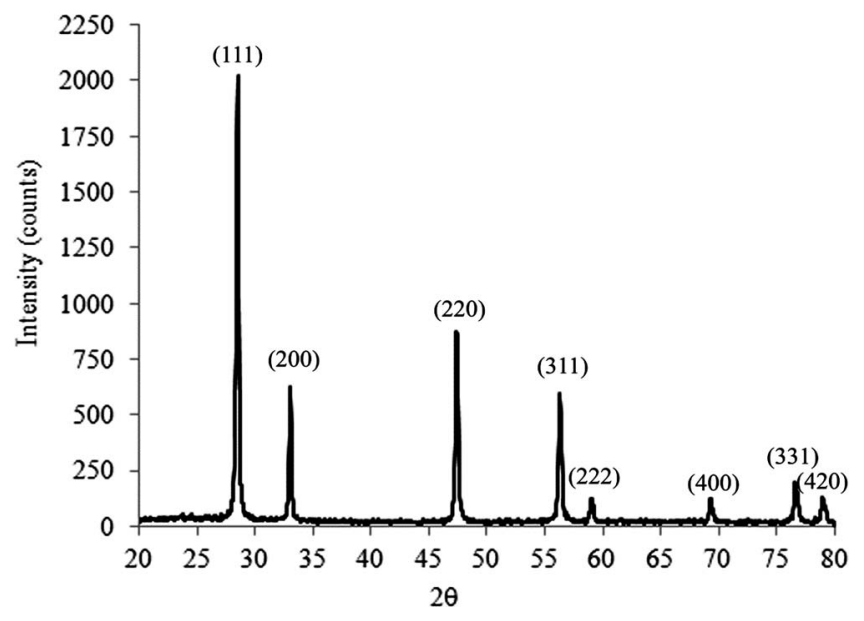

FIG. 3. XRD pattern for as-synthesized CNPs. 

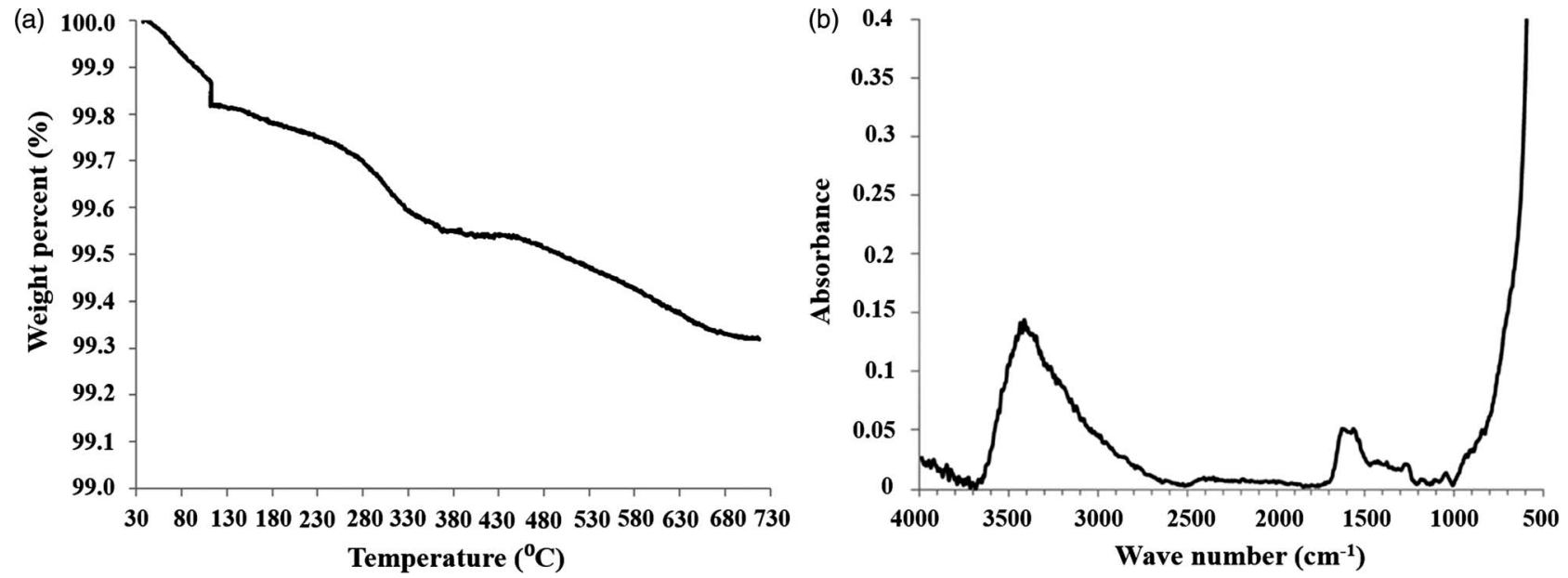

FIG. 4. (a) TG curve and (b) FTIR spectrum for neat CNPs.

attributed to the desorption of physisorbed water from CNP surfaces. Between $110{ }^{\circ} \mathrm{C}$ and $720^{\circ} \mathrm{C}$, the total weight loss in the temperature range was $0.50 \%$ and there was nearly no change of weight above $700{ }^{\circ} \mathrm{C}$. It suggested that $0.50 \%$ weight loss can only come from the dehydration of chemically bound hydroxyl groups at the surface of neat CNPs.

Annealed neat CNPs have also been characterized with FTIR, and typical results are shown in Figure 4(b). FTIR confirms the presence of surface hydroxyl groups, with the broad peak from $3750 \mathrm{~cm}^{-1}$ to $3000 \mathrm{~cm}^{-1}$ and the narrow peak centered at $1600 \mathrm{~cm}^{-1}$ corresponding to the stretching $(\nu-\mathrm{OH})$ and in-plane bending vibration $(\delta-\mathrm{OH})$ of hydroxyl groups, respectively. ${ }^{7}$ The inverted double peak around $2350 \mathrm{~cm}^{-1}$ is attributed to trace $\mathrm{CO}_{2}$, though the absence of any peaks at $1750 \mathrm{~cm}^{-1}$ suggests that no carboxylic surface groups are present.

Given that XRD has excluded the presence of $\mathrm{Ce}(\mathrm{OH})_{3}$ and TGA has excluded $\mathrm{Ce}(\mathrm{OH})_{4}$, FTIR-detected hydroxyl groups can be identified as surface adsorbates. Therefore, the surface density of chemically bound hydroxyl groups $\left(\Omega_{\mathrm{OH}}^{\exp }\right.$, $\mathrm{nm}^{-2}$ ) can be estimated as the ratio of the number of hydroxyl groups lost per unit mass of CNPs $\left(n_{\mathrm{OH}}, \mathrm{g}^{-1}\right)$ to the CNP surface area per unit mass $\left(\mathrm{S}, \mathrm{nm}^{2} \mathrm{~g}^{-1}\right)$, where

$$
\begin{gathered}
n_{\mathrm{OH}}=\frac{2 N_{A} W_{\mathrm{H}_{2} \mathrm{O}}}{M_{\mathrm{H}_{2} \mathrm{O}} W_{\text {final }}}, \\
S=\frac{6 a^{2}}{a^{3} \rho}=\frac{6}{a \rho} .
\end{gathered}
$$

Here the desorption of one $\mathrm{H}_{2} \mathrm{O}$ molecule corresponds to the removal of two hydroxyl groups, accounting for the factor of two in the numerator for $n_{\mathrm{OH}}$. Further, $N_{A}$ is Avogadro's number, $W_{\mathrm{H}_{2} \mathrm{O}}$ the mass fraction of water removed between $110^{\circ} \mathrm{C}$ and $720{ }^{\circ} \mathrm{C}, M_{\mathrm{H}_{2} \mathrm{O}}$ the molecular weight of water, $W_{\text {final }}$ the mass fraction remaining after TGA (that is, the mass fraction of neat CNPs), $a$ the average size of CNPs (here, $30 \mathrm{~nm}$ ), and $\rho$ the density of bulk $\mathrm{CeO}_{2}\left(7.65 \mathrm{~g} \mathrm{~cm}^{-3}\right)$. This gives an estimate of $\Omega_{\mathrm{OH}}^{\text {exp }}=12.9$ chemically bound hydroxyl groups per $\mathrm{nm}^{2}$ of CNP surface.

\section{Computational prediction of surface group density on OH-terminated $\sim 30 \mathrm{~nm}$ CNPs}

\section{Calculated surface group density on $\sim 1 \mathrm{~nm}$ CNPs}

While FTIR and TGA can be used to confirm the presence of and estimate the surface density of adsorbed hydroxyl groups on CNPs, these techniques provide limited insight into the structural arrangement of these hydroxyl groups, or the chemical and physical parameters leading to particular observed surface densities. To probe these issues, initial cubic CNPs with different surface configurations were constructed (see details in Sec. II C) and relaxed to their lowest energy configurations using quantum mechanical calculations based on DFT. It should be noted that, unlike orbital-based DFT calculations in which the presence and arrangement of $\mathrm{Ce}^{3+}$ and $\mathrm{Ce}^{4+}$ cations must be known and specified a priori, such information is an output of planewave DFT calculations. Specifically, Bader charge analysis, ${ }^{24}$ an analytic procedure by which electron charge density is assigned to nearby atoms, can be used to determine the charge states of individual atoms given the DFT-calculated electron density. Comparison of calculated Bader charges to results for systems with known formal oxidation states (e.g., bulk $\mathrm{CeO}_{2}$ and $\mathrm{Ce}_{2} \mathrm{O}_{3}$ ) then allow assignment of formal oxidation states directly from quantum mechanically calculated charge densities.

The stability of various relaxed CNP structures is compared by calculating their excess formation energy relative to bulk $\mathrm{CeO}_{2}$ according to Eqs. (3), (4), and (8). In determining relevant values for $\mu_{\mathrm{O}}$ and $\mu_{\mathrm{H}}$, we note that CNP synthesis is typically conducted in the presence of both $\mathrm{O}_{2}$ gas and $\mathrm{H}_{2} \mathrm{O}$ vapor, and that the ambient temperature $(T)$ and relative partial pressures of $\mathrm{O}_{2}$ gas $\left(p_{\mathrm{O}_{2}}\right)$ and $\mathrm{H}_{2} \mathrm{O}$ vapor $\left(p_{\mathrm{H}_{2} \mathrm{O}}\right)$ completely determine both $\mu_{\mathrm{O}}$ and $\mu_{\mathrm{H}}$ (see details in Sec. II B). For experimentally relevant temperatures $\left(25\right.$ to $\left.650{ }^{\circ} \mathrm{C}\right)$ and pressures atm $\left(10^{-16}\right.$ to $\left.10^{2}\right), \mu_{\mathrm{O}}\left(\mu_{\mathrm{H}}\right)$ varies between -4.65 and $-6.90 \mathrm{eV}(-4.75$ and $-6.93 \mathrm{eV})$. As energy is not an absolute quantity, we take $\mu_{C e}=0 \mathrm{eV}$ as a global reference energy.

For hydrothermal synthesis conditions of small CNPs (typically $T<200^{\circ} \mathrm{C}, p_{\mathrm{O}_{2}}$ less than $1 \mathrm{~atm}$, and $p_{\mathrm{H}_{2} \mathrm{O}}$ less than 


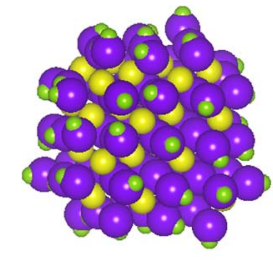

$\mathrm{Ce}_{32} \mathrm{O}_{81} \mathrm{H}_{54}$

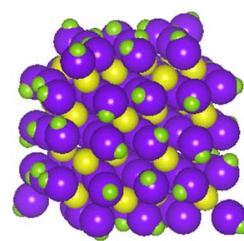

$\mathrm{Ce}_{32} \mathrm{O}_{85} \mathrm{H}_{58}$

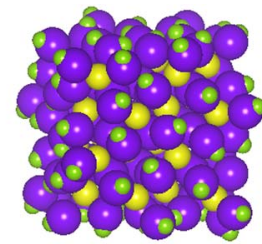

$\mathrm{Ce}_{32} \mathrm{O}_{101} \mathrm{H}_{74}$

- $\mathrm{H}$
FIG. 5. The relaxed, ground-state atomic structures of three OH-terminated CNPs with different hydroxyl group surface densities. Yellow balls represent $\mathrm{Ce}$ atoms, purple balls represent $\mathrm{O}$ atoms, and green balls represent $\mathrm{H}$ atoms. For increasing hydroxyl group surface densities, $-\mathrm{OH}$ groups are first adsorbed on CNP faces, then edges and corners.

$1 \mathrm{~atm}$ ), the excess formation energy of OH-terminated CNPs decreases with increasing numbers of bound hydroxyl surface groups, and achieves a minimum for 74 hydroxyl groups $\left(\mathrm{Ce}_{32} \mathrm{O}_{101} \mathrm{H}_{74}\right)$. Figure 5 shows relaxed structures for various $-\mathrm{OH}$ terminated CNPs, including the low energy $\mathrm{Ce}_{32} \mathrm{O}_{101} \mathrm{H}_{74}$ structure, and highlights the distribution of bound hydroxyl groups at CNP faces, edges, and corners. The 74 hydroxyl groups on $\mathrm{Ce}_{32} \mathrm{O}_{101} \mathrm{H}_{74}$ CNPs are negatively charged, each exhibiting Bader charges consistent with a formal oxidation state of -1 . All 27 "bulk-like" lattice $\mathrm{O}$ atoms (single $\mathrm{O}$ atoms within the CNP and each coordinated to $4 \mathrm{Ce}$ atoms) are also negatively charged, exhibiting Bader charges consistent with formal oxidation states of -2 , and all $32 \mathrm{Ce}$ atoms are positively charged, each with Bader charges consistent with a formal oxidation state of +4 . This leads to a straightforward explanation for the low-energy number of bound hydroxyl groups at the surface of CNP structures: that is, the number required to fully oxidize all $\mathrm{Ce}$ atoms in the CNP. Hence, $\mathrm{Ce}_{32} \mathrm{O}_{101} \mathrm{H}_{74}$ CNPs have 128 net (formal) positive charges (from the $32 \mathrm{Ce}+4$ atoms) and 54 negative charges (from the 27 bulk $\mathrm{O}-2$ atoms), therefore requiring exactly 74 negatively charged hydroxyl groups to give a net neutral CNP. Finally, we note that the CNP geometries considered here have $\sim 1 \mathrm{~nm}$ side lengths, and therefore $\sim 6 \mathrm{~nm}^{2}$ of surface area, giving a predicted stable surface density of bound hydroxyl groups of $\Omega_{\mathrm{OH}}^{\text {calc }}=12.3 \mathrm{~nm}^{-2}$.

\section{Scaling $\sim 1 \mathrm{~nm}$ results to predict surface group densities on hydroxyl-terminated $\sim 30 \mathrm{~nm}$ CNPs}

Considering cubic CNP structures with sizes of $1 \mathrm{~nm}, 1.5$ $\mathrm{nm}$, and $2 \mathrm{~nm}$ reveals the relationship between the number of $\mathrm{Ce}$ and/or $\mathrm{O}$ atoms and CNP size. For a CNP with a size of $N$ $\mathrm{nm}$ (and therefore containing approximately $(2 N)^{3}$ ceria unit cells), the number of Ce atoms scales as approximately $32 N^{3}$ and the number of bulk $\mathrm{O}$ atoms ( $\mathrm{O}$ atoms internal to the $\mathrm{CNP}$ ) scales as approximately $(4 N-1)^{3}$. Since the formal positive charge is contributed from $\mathrm{Ce}$ atoms, in the case that each $\mathrm{Ce}$ is fully oxidized (+4), CNPs will have $128 N^{3}$ net formal positive charges. Similarly, the net formal negative charge contributed from bulk $\mathrm{O}$ atoms is $2(4 N-1)^{3}$, with each bulk $\mathrm{O}$ atom contributing -2 . Therefore, if all remaining formal positive charges in a fully oxidized CNP, (that is, $128 N^{3}-2(4 N$

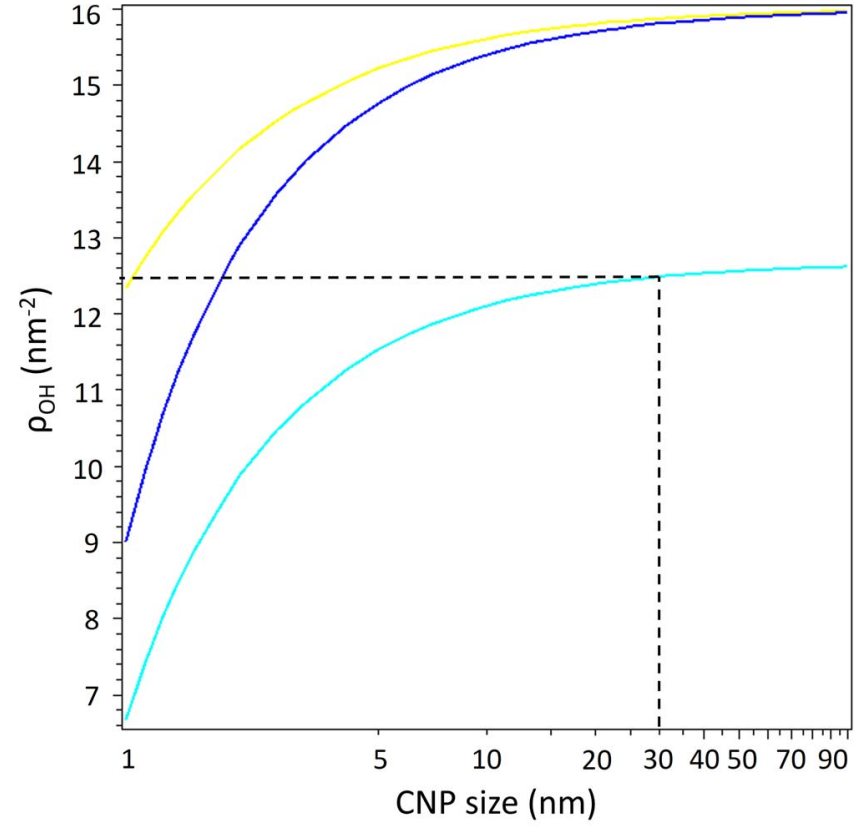

FIG. 6. Density of surface-adsorbed hydroxyl groups as a function of CNP size calculated from a scaling relationship invoking full oxidation of $\mathrm{Ce}$ atoms (see text for details). Yellow, blue, and cyan curves are plotted for CNP surface terminations consistent with $\mathrm{Ce}_{32} \mathrm{O}_{101} \mathrm{H}_{74}, \mathrm{Ce}_{32} \mathrm{O}_{125} \mathrm{H}_{54}$, and $\mathrm{Ce}_{32} \mathrm{O}_{120} \mathrm{H}_{40}$ structures, respectively. In addition, the yellow curve represents the case where $-\mathrm{OH}$ is the only surface species to balance net positive charges from $\mathrm{Ce}^{4+}$ cations, while blue and cyan curves represent the case where both $-\mathrm{OH}$ and $-\mathrm{O}_{x}$ surface groups are present. Colors have been selected to match subsequent figure (Figure 7).

$-1)^{3}$ ) are balanced with surface hydroxyl groups each contributing a formal charge of -1 , we may calculate the surface hydroxyl density, $\Omega_{\mathrm{OH}}^{\text {calc }}$, as

$$
\Omega_{\mathrm{OH}}^{\text {calc }}=\frac{128 N^{3}-2(4 N-1)^{3}}{6 N^{2}}=\frac{96 N^{2}-24 N+2}{6 N^{2}} .
$$

In the limit of large CNPs $(N \rightarrow \infty)$, therefore, fully oxidized and hydroxylated CNPs have $\Omega_{\mathrm{OH}}^{\text {calc }}=16$, or one $-\mathrm{OH}$ group per $\{001\}$ oxygen lattice site. This is intuitively correct, as $\{001\}$ surface anion lattice sites are four-fold coordinated, with half the cation neighbors of bulk anion sites. Finite-sized CNPs, particular those with sizes $\sim 30 \mathrm{~nm}$ and smaller, have lower surface hydroxyl group densities, even when fully oxidized. Specifically, the surface density of bound hydroxyl groups as a function of CNP size is predicted to be $12.3 \mathrm{~nm}^{-2}$ for $\sim 1 \mathrm{~nm}$ CNPs, and $15.8 \mathrm{~nm}^{-2}$ for CNPs with side lengths of $\sim 30 \mathrm{~nm}$ (see yellow curve in Figure 6). Therefore, based on results for OH-terminated $\sim 1 \mathrm{~nm}$ CNPs, calculations predict a surface hydroxyl group density of $15.8 \mathrm{~nm}^{-2}$ for $\sim 30 \mathrm{~nm}$ CNPs, a surface density 33\% higher than the experimentally measured value of $12.9 \mathrm{~nm}^{-2}$. Partial reduction of such CNPs can reduce the surface density in proportion to the percent of $\mathrm{Ce}^{4+}$ cations reduced to $\mathrm{Ce}^{3+}$. Achieving quantitative agreement between calculated and experimentally observed surface hydroxyl densities entirely through CNP reduction, therefore, would require that $\sim 33 \%$ of $\mathrm{Ce}^{4+}$ cations be reduced to $\mathrm{Ce}^{3+}$. 


\section{Accounting for mixed $-\mathrm{O}_{x}$ and $-\mathrm{OH}$ surface terminations for small CNPs}

\section{Determination of stable mixed termination surface structures for $\sim 1 \mathrm{~nm}$ CNPs}

Scaling calculated surface group densities from $\sim 1 \mathrm{~nm}$ OH-terminated CNPs yields predicted surface hydroxyl densities that are $\sim 33 \%$ higher than the experimentally measured densities $\left(\Omega_{\mathrm{OH}}^{\text {calc }}=15.8 \mathrm{~nm}^{-2}>\Omega_{\mathrm{OH}}^{\text {exp }}=12.9 \mathrm{~nm}^{-2}\right.$ for $\sim 30$ $\mathrm{nm}$ CNPs). This discrepancy can be attributed to a number of factors, including (i) kinetic limitations preventing removal of all hydroxyl groups (arising because at low surface densities, $-\mathrm{OH}$ removal is limited by the requirement that two bound $\mathrm{OH}$ groups combine to form the desorbing species, $\mathrm{H}_{2} \mathrm{O}$ ), (ii) misidentification of some chemically bound surface hydroxyl groups as physisorbed (as noted above, we have assumed that all mass loss during TGA occurring below $110{ }^{\circ} \mathrm{C}$ is solely due to physisorbed surface species), (iii) the possibility that at finite temperature as-synthesized CNPs are not fully oxidized (as is the case for bulk ceria samples, see examples ${ }^{29,30}$ ), or (iv) that more tightly bound surface species other than hydroxyl groups are present on as-synthesized CNPs.

While all of these effects are likely influencing the measured surface areal density of hydroxyl groups reported here, the last explanation - that surface species other than hydroxyl groups may be present on as-synthesized CNPs-highlights the fact that CNPs are generally synthesized and applied in environments where both $\mathrm{O}_{2}$ gas and $\mathrm{H}_{2} \mathrm{O}$ vapor are abundant. This suggests that $\mathrm{O}$-containing species other than hydroxyl groups, e.g., $-\mathrm{O},-\mathrm{O}_{2}$, and/or $-\mathrm{O}_{3}$ groups, may be present as surface adsorbed anions, reducing the effective density of surface $-\mathrm{OH}$ groups. By constructing atomistic systems containing both $-\mathrm{OH}$ and $-\mathrm{O}_{x}$ surface groups, we have calculated the relative stability of CNPs with mixed $-\mathrm{OH} /-\mathrm{O}_{x}$ surface terminations. Figure 7 plots a phase diagram stable CNP terminations as a function of $\mu_{\mathrm{O}}$ and $\mu_{\mathrm{H}}$ in this study. The relative

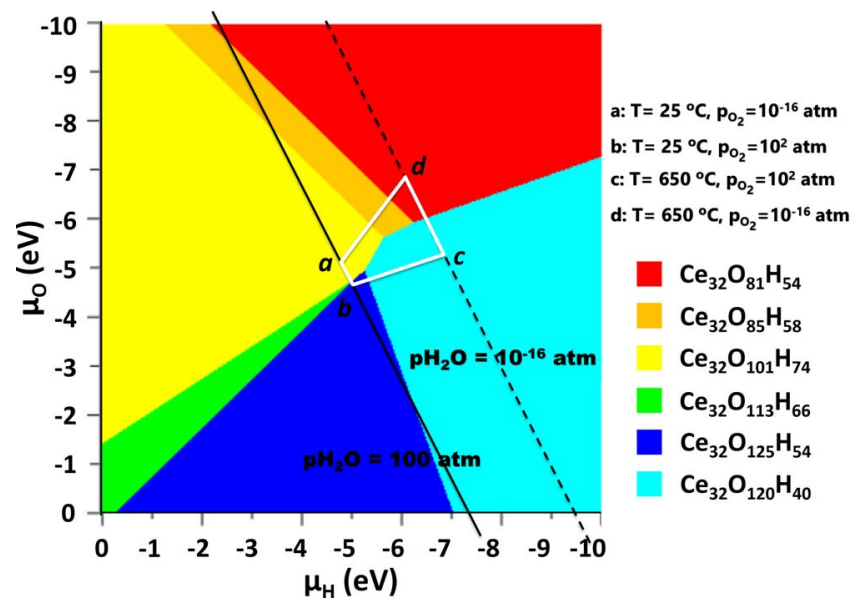

FIG. 7. Phase diagram of ground state surface terminations for small CNPs as a function of $\mu_{\mathrm{O}}$ and $\mu_{\mathrm{H}}$ in a gas phase environment containing $\mathrm{O}_{2}$ and $\mathrm{H}_{2} \mathrm{O}$. Warm colors indicate structures terminated solely with hydroxyl groups (see atomic structures in Figure 5). Cool colors indicate structures with mixed $-\mathrm{OH}$ and $-\mathrm{O}_{x}$ terminations (see atomic structures in Figure 8). Black parallel lines indicate the experimentally relevant limits of $\mathrm{H}_{2} \mathrm{O}$ partial pressure. The white trapezoid abcd indicates the region of experimental conditions most relevant for CNP synthesis and application.

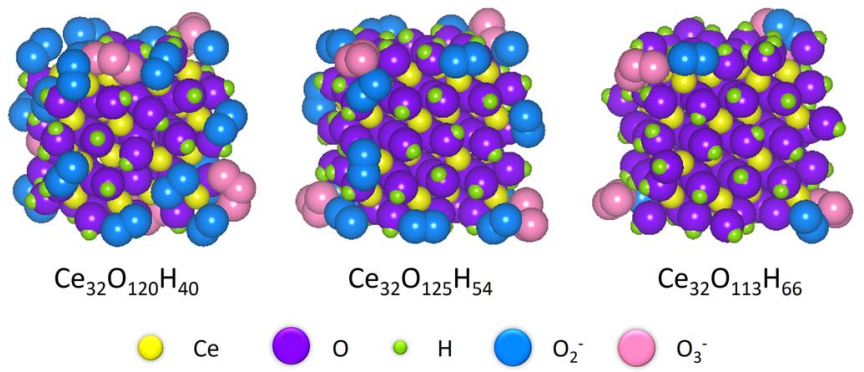

FIG. 8. The relaxed, ground-state atomic structures of three mixed -OH and $-\mathrm{O}_{x}$ terminated CNPs. Yellow balls represent $\mathrm{Ce}$ atoms, purple balls represent either bulk $\mathrm{O}$ atoms or $\mathrm{O}$ atoms in $-\mathrm{OH}$ surface groups, green balls represent $\mathrm{H}$ atoms, blue balls represent $\mathrm{O}$ atoms in $\mathrm{O}_{2}^{-}$surface groups, and pink balls represent $\mathrm{O}$ atoms in $\mathrm{O}_{3}^{-}$surface groups. For increasing numbers of surface adsorbed $-\mathrm{O}_{x}$ surface groups, these species absorb first on CNP corners, then edges.

stability of these various surface configurations is determined as above from Eqs. (3), (4), and (8).

In calculating the excess formation energies of CNPs with various surface configurations, we invoke the fact that in an equilibrium phase environment containing both $\mathrm{O}_{2}$ gas and $\mathrm{H}_{2} \mathrm{O}$ vapor, $\mu_{\mathrm{O}}$ and $\mu_{\mathrm{H}}$ are not independent, but must satisfy the relation $2 \mu_{\mathrm{H}}+\mu_{\mathrm{O}}=\mu_{\mathrm{H}_{2} \mathrm{O}}$, with $\mu_{\mathrm{H}_{2} \mathrm{O}}$ the chemical potential of $\mathrm{H}_{2} \mathrm{O}$ vapor. Moreover, the chemical potential values considered can be connected to experimentally measured enthalpies of $\mathrm{O}_{2}$ gas and $\mathrm{H}_{2} \mathrm{O}$ vapor as a function of ambient temperature $(T)$ and the partial pressures of $\mathrm{O}_{2}$ gas $\left(p_{\mathrm{O}_{2}}\right)$ and $\mathrm{H}_{2} \mathrm{O}$ vapor $\left(p_{\mathrm{H}_{2} \mathrm{O}}\right)$. In this way, experimental values of $T$ and $p_{\mathrm{O}_{2}}$ and $p_{\mathrm{H}_{2} \mathrm{O}}$ (that is, the measured conditions under which a CNP is synthesized or applied) can be mapped into chemical potential values that define an experimentally relevant range of conditions. The mapping of environmental conditions ( $T$ and $p$ ) in chemical potentials is nonlinear, and defined by Eqs. (4) and (8). To facilitate use of the phase diagram in Figure 7, a web-based tool implementing Eqs. (4) and (8) has been made available to convert experimental conditions to chemical potentials (see http://www.engr.uky.edu/ beck/mu-calc.html). The tool allows input of $T, p_{\mathrm{O}_{2}}$, and $p_{\mathrm{H}_{2} \mathrm{O}}$ values and returns $\mu_{\mathrm{O}}$ and $\mu_{\mathrm{H}}$ values for the specified condition. In this way, the computationally-predicted stable surface termination for any given experimental conditions can be determined directly from Figure 7.

Considering Figure 7 itself, we note that within the upper half of the phase diagram $\left|\mu_{\mathrm{O}}\right|$ is high, and stable CNPs are terminated solely with hydroxyl groups (structures indicated by warm colors in Figure 7, also see atomic structures in Figure 5). In contrast, within the lower half of the phase diagram, where $\left|\mu_{\mathrm{O}}\right|$ is low, stable CNPs exhibit mixed $-\mathrm{OH} /-\mathrm{O}_{x}$ terminations (structures indicated by cool colors in Figure 7, also see atomic structures in Figure 8). Low-energy mixed-termination CNP structures have adsorbed $-\mathrm{O}_{2}$ and $-\mathrm{O}_{3}$ surface groups preferentially adsorbed at CNP edges and corners, as shown in Figure 8. Based on Bader charge analysis, the oxidation state of $-\mathrm{O}_{x}$ surface groups can be determined by the same procedure applied above for-OH-only terminations. For the $\mathrm{Ce}_{32} \mathrm{O}_{125} \mathrm{H}_{54}$ and $\mathrm{Ce}_{32} \mathrm{O}_{113} \mathrm{H}_{66}$ structures, 
all surface groups $\left(-\mathrm{OH}\right.$ and $-\mathrm{O}_{x}$ ) have formal charges of -1 , while for the $\mathrm{Ce}_{32} \mathrm{O}_{120} \mathrm{H}_{40}$ structure, a subset of $-\mathrm{O}_{x}$ groups have formal charges of -2 . In all cases of CNPs with mixed $\mathrm{OH}$ and $-\mathrm{O}_{x}$ terminations, the sum of formal negative charges (-OH groups plus $-\mathrm{O}_{x}$ groups) equals the sum of formal positive charges from fully oxidized $\mathrm{Ce}(+4)$ atoms. Hence the evolution of stable surface structures is simply a reallocation of surface groups among $-\mathrm{OH}$ and $-\mathrm{O}_{x}$ in response to changes in the specific combination of $\mu_{\mathrm{O}}$ and $\mu_{\mathrm{H}}$ such that the charge neutrality of all considered CNP structures is maintained.

From an experimental perspective, we note that increasing the magnitude of $\left|\mu_{\mathrm{O}}\right|$ (or $\left|\mu_{\mathrm{H}}\right|$ ), e.g., by lowering $p_{\mathrm{O}_{2}}$ (or $p_{\mathrm{H}_{2} \mathrm{O}}$ ), represents increasing the difficulty of obtaining $\mathrm{O}$ (or H) from the environment. Similarly, increasing the temperature increases the difficulty in binding $\mathrm{O}$ or $\mathrm{H}$, and therefore increases the magnitude of both $\left|\mu_{\mathrm{O}}\right|$ and $\left|\mu_{\mathrm{H}}\right|$. Under typical experimental conditions for synthesizing, characterizing, and applying CNPs, the temperature is held between $25^{\circ} \mathrm{C}$ and $650{ }^{\circ} \mathrm{C}$, and partial pressures of $\mathrm{O}_{2}$ gas and $\mathrm{H}_{2} \mathrm{O}$ vapor range between $10^{2}$ and $10^{-16} \mathrm{~atm}$. These pressures constrain accessible chemical potential values between black solid and dotted lines in Figure 7. Further, the temperature constraints limit the accessible phase space to that enclosed by the white trapezoid $a b c d$-precisely the chemical potential range within which transitions in the stable CNP surface termination are concentrated.

Previous calculations on bulk-terminated ceria slabs and nanoparticles have shown that subtle changes in atomic positions can lead to different minimum energy arrangements of $3+$ and $4+$ charge states on Ce cations. ${ }^{31,32}$ These variations have been shown to result in up to a $0.03 \mathrm{eV}$ per $\mathrm{Ce}$ atom $(0.03 \mathrm{eV} / \mathrm{Ce})$ change in the total energy of bulk-terminated CNPs. ${ }^{32}$ While direct calculation of the energies of different $3+/ 4+$ charge state rearrangements in partially reduced CNPs is beyond the scope of the present paper, we note that (i) energy effects of the magnitude reported for varying arrangements of $3+/ 4+\mathrm{Ce}$ cations in CNPs $\left(0.03 \mathrm{eV} / \mathrm{Ce}^{32}\right)$ will not appreciably alter the phase stabilities reported in Figure 7, and (ii) such effects are only applicable to partially reduced CNPs.

In terms of experimental synthesis conditions, when $\mathrm{H}_{2} \mathrm{O}$ vapor is the major source of $\mathrm{H}$ (as assumed here), pure $\mathrm{OH}$ terminated CNPs can be fabricated by constraining temperatures to below $350{ }^{\circ} \mathrm{C}$ and handling CNPs under relatively high partial pressures of $\mathrm{H}_{2} \mathrm{O}$ vapor (e.g., ambient humidity levels). In contrast, mixed $-\mathrm{OH}$ and $-\mathrm{O}_{x}$ terminated CNPs are expected from synthesis occurring above $350{ }^{\circ} \mathrm{C}$ and under relatively low partial pressures of $\mathrm{H}_{2} \mathrm{O}$ (e.g., dry air). In addition, increasing $p_{\mathrm{O}_{2}}$ (e.g., to greater than $1 \mathrm{~atm}$ ) favors the formation of mixed $-\mathrm{OH}$ and $-\mathrm{O}_{x}$-terminated CNPs, and increasing temperature generally leads to reduced numbers of hydroxyl groups and increased numbers of $-\mathrm{O}_{x}$ surface groups at the surface of CNPs.

\section{Surface hydroxyl density as a function of CNP size for $\mathrm{OH}+\mathrm{O}_{x}$-terminated CNPs}

Accounting for negative charges provided by $-\mathrm{O}_{x}$ surface groups in addition to hydroxyl groups (e.g., as in the
$\mathrm{Ce}_{32} \mathrm{O}_{120} \mathrm{H}_{40}$ and $\mathrm{Ce}_{32} \mathrm{O}_{125} \mathrm{H}_{54}$ structures), the surface density of hydroxyl groups will be reduced compared to the case where only hydroxyl surface groups are present. From the pattern of adsorbed surface groups on the $\mathrm{Ce}_{32} \mathrm{O}_{120} \mathrm{H}_{40}$ and $\mathrm{Ce}_{32} \mathrm{O}_{125} \mathrm{H}_{54}$ structures found here (Figure 8) and the results of Bader charge analysis, we can develop expressions for the surface hydroxyl density analogous to Eq. (11). For $\mathrm{Ce}_{32} \mathrm{O}_{125} \mathrm{H}_{54},-\mathrm{O}_{x}$ surface groups appear only at CNP corners and edges, and all have Bader charges indicating formal charges of -1 . For CNPs with side lengths of $N \mathrm{~nm}$, four corner $\mathrm{Ce}$ atoms are present, each binding $2 \mathrm{O}_{x}^{-}$groups. In addition, a single $\mathrm{O}_{x}^{-}$binds on each of $12 \mathrm{~N}$ nm lengths of CNP edges. This gives a total negative contribution from $-\mathrm{O}_{x}$ surface groups species of $-1 \cdot(4 \cdot 2+12 N)$. This leaves net negative charge of $128 N^{3}-2(4 N-1)^{3}-8-12 N$ to be accounted for by hydroxyl groups, yielding a surface density of hydroxyl groups, $\Omega_{\mathrm{OH}}^{\text {calc }}$ of

$$
\begin{aligned}
\Omega_{\mathrm{OH}}^{\text {calc }} & =\frac{128 N^{3}-2(4 N-1)^{3}-8-12 N}{6 N^{2}} \\
& =\frac{96 N^{2}-36 N-6}{6 N^{2}}
\end{aligned}
$$

For $\mathrm{Ce}_{32} \mathrm{O}_{120} \mathrm{H}_{40}$, some face sites are also occupied by $-\mathrm{O}_{x}$ surface groups. These 5 face sites are occupied by $-\mathrm{O}_{x}^{2-}$ surface groups (that is, $-\mathrm{O}_{x}$ groups with Bader charges consistent with formal charges of -2 ). Similar to the $\mathrm{Ce}_{32} \mathrm{O}_{125} \mathrm{H}_{54}$ structure, 4 corner sites, and 10 edge sites are also occupied by $-\mathrm{O}_{x}^{-}$groups. Assuming the relative ratio of all $-\mathrm{O}_{x}$ surface groups remains unchanged as CNP size is increased, total net negative charge provided by all $-\mathrm{O}_{x}$ surface groups will be $4+10 N+10 N^{2}$. This leaves net negative charge of $128 N^{3}-2(4 N-1)^{3}-4-10 N-10 N^{2}$ to be accounted for by hydroxyl groups, yielding a surface density of hydroxyl groups $\Omega_{\mathrm{OH}}^{\text {calc }}$ of

$$
\begin{aligned}
\Omega_{\mathrm{OH}}^{\text {calc }} & =\frac{128 N^{3}-2(4 N-1)^{3}-4-10 N-10 N^{2}}{6 N^{2}} \\
& =\frac{76 N^{2}-34 N-2}{6 N^{2}}
\end{aligned}
$$

For the experimental conditions used to synthesize 20$40 \mathrm{~nm}$ CNPs in this study (finally dried at $T=75^{\circ} \mathrm{C}$ and $p_{\mathrm{O}_{2}}$ $\left.=0.2 \mathrm{~atm} p_{\mathrm{H}_{2} \mathrm{O}}=10^{-7} \mathrm{~atm}\right), \mu_{\mathrm{O}}$ is calculated as $-4.78 \mathrm{eV}$ and $\mu_{\mathrm{H}}$ as $-5.30 \mathrm{eV}$. These chemical potentials are predicted to yield a $\mathrm{Ce}_{32} \mathrm{O}_{120} \mathrm{H}_{40}$ structure with mixed surface termination (see Figure 8), which, due to the presence of $-\mathrm{O}_{x}$ surface groups, is expected to have a lower effective surface density of hydroxyl groups than pure -OH terminated CNPs. This is consistent with the fact that computationally predicted $-\mathrm{OH}$ surface densities on the $\sim 30 \mathrm{~nm}$ CNPs are $\sim 33 \%$ higher than measured values for experimentally synthesized CNPs. Applying Eq. (13), we find that $\sim 30 \mathrm{~nm}$ CNPs with surface terminations consistent with the $\mathrm{Ce}_{32} \mathrm{O}_{120} \mathrm{H}_{40}$ structure are predicted to have $\Omega_{\mathrm{OH}}^{\text {calc }} \approx 12.5$ adsorbed hydroxyl groups per $\mathrm{nm}^{2}$ (see cyan curve in Figure 6) - extremely close to the experimentally measured value of $\Omega_{\mathrm{OH}}^{e x p}=12.9 \mathrm{~nm}^{-2}$. 


\section{CONCLUSION}

Experimental characterization of small CNPs reveals the presence of adsorbed $-\mathrm{OH}$ groups at $\mathrm{CNP}$ surfaces, but cannot reveal the atomic scale arrangement of adsorbed surface groups. Atomistic quantum mechanical calculations have been used to determine these configurations. Assuming $\mathrm{OH}$ as the only surface functional group present at CNP faces, edges, and corners results in computationally-predicted surface hydroxyl group densities $\sim 33 \%$ higher than experimentally measured densities. This discrepancy can be rectified by considering the possibility that both $-\mathrm{O}_{x}$ and $-\mathrm{OH}$ surface functional groups are present. Combining calculated excess formation energies of mixed $-\mathrm{OH} /-\mathrm{O}_{x}$ terminated CNPs with previously tabulated thermochemical data yields a phase diagram for CNP surface functionalizations as a function of $\mathrm{O}$ and $\mathrm{H}$ chemical potential. These results demonstrate that tuning the environmental conditions under which CNPs are synthesized and/or applied can have a significant impact on the surface termination of small CNPs. For conditions involving $\mathrm{O}_{2}$ gas and $\mathrm{H}_{2} \mathrm{O}$ vapor, we have shown that the distribution of surface adsorbed $-\mathrm{OH}$ and $-\mathrm{O}_{x}$ groups can be varied by changing the temperature and partial pressure of $\mathrm{O}_{2}$ gas and $\mathrm{H}_{2} \mathrm{O}$ vapor. These results not only provide an initial map for the design of CNPs with controlled surface terminations, but demonstrate that combined computational and experimental studies can be leveraged to reveal the detailed structure and properties of small CNPs.

\section{ACKNOWLEDGMENTS}

The authors Xing Huang and Matthew J. Beck acknowledge high performance computing resources provided by Center for Computational Sciences at University of Kentucky. The authors Binghui Wang and Eric A. Grulke acknowledge the support by United States Environmental Protection Agency Science [Grant No. RD-833772]. Although the research described in this article has been funded wholly or in part by the United States Environmental Protection Agency through STAR Grant No. RD-833772, it has not been subjected to the Agencies required peer and policy review and, therefore, does not necessarily reflect the views of the Agency and no official endorsement should be inferred.

${ }^{1}$ S. Carrettin, P. Concepción, A. Corma, J. M. López Nieto, and V. F. Puntes, Angew. Chem., Int. Ed. 43, 2538-2540 (2004).

${ }^{2}$ A. Primo, T. Marino, A. Corma, R. Molinari, and H. García, J. Am. Chem. Soc. 133, 6930-6933 (2011).
${ }^{3}$ J. A. Rodriguez, J. Graciani, J. Evans, J. B. Park, F. Yang, D. Stacchiola, S. D. Senanayake, S. Ma, M. Pérez, P. Liu, J. Fdez Sanz, and J. Hrbek, Angew. Chem., Int. Ed. 48, 8047-8050 (2009).

${ }^{4}$ C. Gaudillèrea, P. Vernouxa, C. Mirodatosa, G. Cabocheb, and D. Farrusseng, Catal. Today 157, 263-269 (2010).

${ }^{5}$ S. Babu, A. Velez, K. Wozniak, J. Szydlowska, and S. Seal, Chem. Phys. Lett. 442, 405-408 (2007).

${ }^{6}$ Y. Xue, Q. F. Luan, X. Yang, D. Yao, and K. B. Zhou, J. Phys. Chem. C 115, 4433-4438 (2011).

${ }^{7}$ M. Molinari, S. S. Parker, D. C. Sayle, and M. S. Islam, J. Phys. Chem. C 116, 7073-7082 (2012).

${ }^{8}$ W. Calleja, C. Falcony, A. Torres, M. Aceves, and R. Osorio, Thin Solid Films 270, 114-117 (1995).

${ }^{9}$ W. O. R. Horacio and E. Bergna, Colloidal Silica: Fundamentals and Applications (CRC Press, London, 2006), p. 305.

${ }^{10}$ V. Kanniah, B. H. Wang, Y. Yang, and E. A. Grulke, J. Appl. Polym. Sci. 125, 165-174 (2012).

${ }^{11}$ M. Zawadzki, J. Alloys Compd. 454, 347-351 (2008).

${ }^{12}$ L. Chen, P. Fleming, V. Morris, J. D. Holmes, and M. A. Morris, J. Phys. Chem. C 114, 12909-12919 (2010).

${ }^{13}$ M. Nolan, S. Parker, and G. Watson, J. Phys. Chem. B 110, 2256-2262 (2006).

${ }^{14}$ M. Fronzi, A. Soon, B. Delley, E. Traversa, and C. Stampfl, J. Chem. Phys. 131, 104701 (2009).

${ }^{15}$ H. X. Mai, L. D. Sun, Y. W. Zhang, R. Si, W. Feng, H. P. Zhang, H. C. Liu, and C. H. Yan, J. Phys. Chem. B 109, 24380-24385 (2005).

${ }^{16}$ A. Ansari and A. Kaushik, J. Semicond. 31, 033001 (2010).

${ }^{17}$ G. Kresse and J. Furthmüller, Comput. Mater. Sci. 6, 15-50 (1996).

${ }^{18}$ J. P. Perdew, K. Burke, and M. Ernzerhof, Phys. Rev. Lett. 77, 3865-3868 (1996).

${ }^{19}$ P. E. Blöechl, Phys. Rev. B 50, 17953-19979 (1994).

${ }^{20}$ S. L. Dudarev, G. A. Botton, S. Y. Savrasov, C. J. Humphreys, and A. P. Sutton, Phys. Rev. B 57, 1505-1509 (1998).

${ }^{21}$ J. L. F. Da Silva, M. V. Ganduglia-Pirovano, J. Sauer, V. Bayer, and G. Kresse, Phys. Rev. B 75, 045121 (2007).

${ }^{22}$ M. Fronzi, S. Piccinin, B. Delley, E. Traversa, and C. Stampfl, Phys. Chem. Chem. Phys. 11, 9188-9199 (2009).

${ }^{23} \mathrm{M}$. W. Chase, Jr., NIST-JANAF Thermochemical Tables 4th ed. (American Chemical Society and the American Institute of Physics for the National Institute of Standards and Technology, 1998).

${ }^{24}$ W. Tang, E. Sanville, and G. Henkelman, J. Phys.: Condens. Matter 21, 084204 (2009).

${ }^{25}$ Y. Jiang, J. B. Adams, and M. van Schilfgaarde, J. Chem. Phys. 123, 064701 (2005).

${ }^{26}$ Z. Yang, G. Luo, Z. Lu, and K. Hermansson, J. Chem. Phys. 127, 074704 (2007)

${ }^{27}$ C. W. Castleton, J. Kullgren, and K. Hermansson, J. Chem. Phys. 127, 244704 (2007).

${ }^{28}$ M. Anis-ur Rehman and A. Abdullah, J. Supercond. Nov. Magn. 24, 10951098 (2011)

${ }^{29}$ F. Esch, S. Fabris, L. Zhou, T. Montini, C. Africh, P. Fornasiero, G. Comelli, and R. Rosei, Science 309, 752-755 (2005).

${ }^{30}$ S. Babu, R. Thanneeru, T. Inerbaev, R. Day, A. E. Masunov, A. Schulte, and S. Seal, Nanotechnology 20, 085713 (2009).

${ }^{31}$ M. V. Ganduglia-Pirovano, J. L. F. Da Silva, and J. Sauer, Phys. Rev. Lett. 102, 026101 (2009)

${ }^{32}$ A. Migani, K. M. Neyman, F. Illas, and S. T. Bromley, J. Chem. Phys. 131, 064701 (2009) 